\title{
THE COMPARISON OF DYADIC ADJUSTMENT RATE AND SEXUAL FUNCTION OF INFERTILE AND FERTILE FEMALES REFERRING TO BE'SAT HOSPITAL OF SANANDAJ CITY
}

\author{
Parisa Shahbazi Hesabi \\ MA student of Psychology, Department of Psychology, Sanandaj branch, Islamic Azad University, \\ Sanandaj, Iran \\ Mahmoud Goudarzi \\ Assistance Professor in Psychology, Department of Psychology, Sanandaj branch, Islamic Azad \\ University, Sanandaj, Iran \\ Ronak Shaoei \\ Associate professor in Nursing and Midwifery, Department of Nursing and Midwifery, Kurdistan \\ University of Medical Sciences, , Sanandaj, Iran
}

\begin{abstract}
Introduction and purpose: pregnancy and childbirth are mentally and physiologically required by females, and gestation is the symbol of their self actualization and identity. The stress of infertility causes impairment of dyadic satisfaction, diminution of confidence and depletion of couple's sexual communication times. In this study the purpose was to compare the dyadic adjustment rate and sexual function of infertile and fertile female referring to Be'sat Hospital of Sanandaj city.

Articles and Methods : This research method was the kind of scientific-comparative study, and selecting method of samples was voluntary, therefore 240 female 120 of whom were fertile female referring to Be'sat Hospital Clinic of Sanandaj and 120 infertile ones referring to Be'sat Hospital infertility center of Sanandaj were selected. The Data collection tools include Spanier's Dyadic Adjustment Scale (DAS) questionnaire and Female Sexual Function Index (FSFI), and the U Mann Whitney Test is used to analyze the data.

Findings: The result of the study didn't demonstrate significant differences between the dyadic adjustment rate and the sexual function of fertile and infertile female. In the sub scales of dyadic adjustment the significant difference $(p \leq 0 / 01)$ was only seen in the sub scales of double consistency, agreement and love expression. In the female's sub scales of sexual function, only the vaginal moisture with $(\mathrm{P}=0 / 024)$ was significant and there were no significant differences in other sub scales.

Conclusion: according to the result of this study, the infertility is not supposed to have considerable effect on the dyadic adjustment rate and the infertile female's sexual function, and even in some sub scales the infertile female's dyadic adjustment and sexual function is better than fertile ones.
\end{abstract}

Keywords: dyadic adjustment, sexual function, fertile female, infertile female

\section{INTRODUCTION}

Fertility, reproduction and having children is one of the human's desires and a basis for the human's race durability that some couples may be deprived of it for various reasons. Infertility which is one of the personal and social problems, could expose the suffering people to various psychological pressures. Infertility is defined as the loss of pregnancy after a year of unprotected sexual intercourse (without using the methods of contraception) (1). Infertility is a process impressing on body, occupation, personality and mentality and has negative impacts on the individual's emotions including his self-esteem. Based on the studies about 50 to 80 million people in the world suffer from some types of infertility. So that in every 6 couples around the world, a couple of reproduction age suffers from infertility (2). Infertility is also considered as a stigma in our society and paying attention to the fact that the infertile individual could not follow the reproduction process naturally like other ordinary individuals, makes it more important and becomes a cause of an individual demographic crisis(3). 
Infertility is a common problem and according to the statistics of the world health organization, one of every four couples in developed countries suffers from infertility (4). Infertility is seen in 10 to 15 percent of the US couples (5). There have been a few studies among the infertile couples in Iran as a developing country. In an epidemiologic study in 2004, the prevalence of infertility among Iranian females with an age range 19 to 49 was reported 24.9 percent (6). According to the provided statistics from the ministry of health in 2009 , the prevalence rate of infertility has been estimated 20.2 percent in Iran (7). Infertility has wide and extensive impacts such as the sense of insolvency, conflict, frustration, a sharp drop in self-esteem, social withdrawal and isolation, melancholy, identity difficulty, the sense of lack of beauty and life absurdity on people. Infertility has also been a very stressful evolution to the couples and their dyadic and family life and cause great difficulties in their relation. Many problems including difficulty in relation with each other and those around, sexual love making actions, decision making, the process of emotional and excitement health and even psychological transformation occur in infertile couples facing infertility(8). Downey and Mackinney represented that the females referring for the infertility treatment have had high rates of depression, anxiety and stress and had low twosome agreement, correlation and dyadic adjustment(9). By the definition of consistency Greef states that the compatible couples are those having great agreement with each other, satisfied with the type and level of their relation, the type and quality of leisure time and apply a well management in the area of their time and financial issues(10).

Since an active and effective sexual communication could increase the possibility of fertility, the impairment of sexual function in infertile female is supposed to be more than fertile ones (11). The infertile couples represent lower levels of satisfaction in sexual function (12). The stress of infertility also decrease the sexual self-confidence and has negative effect on sexual function and frequency times of sexual intercourse (13). Infertility causes many psychological consequences to individuals which could be one of the individual's most virulent experiences in life and it becomes a cause of a psychological crisis to individuals. Having children is one of the main goals of family formation and marriage, thus the problem of infertility could participate in creating stress in family. The stress of infertility causes impairment of dyadic satisfaction, diminution of self-confidence and the frequency times of couple's sexual function(14). The purpose of this research is to study the comparison of the rate of dyadic adjustment and sexual function of infertile and fertile females referring to Be'sat Hospital of Sanandaj city.

\section{RESEARCH METHODOLOGY}

The method of this study is the kind of Scientific-comparative or casual-comparative research. the data collecting type is through the field research methods and using questionnaire. the studied community was constituted of referring females to the female's clinic and the infertility center of Be'sat hospital in 2014 which 240 individuals were selected as samples through purposive sampling among them that they were constituted of 120 infertile and 120 fertile individuals. Regarding the protection of privacy policy, every female were conducted to a private place and the purpose of research were explained to them and in case of acceptance to take part in the research they entered the study.

The subjects were assured that the information of the questionnaire would remain confidential. The inclusion criteria in the infertile female's group included:

Ages 16 to 50 years old, living with spouse, elapsing at least two years of the date of marriage, lack of ovarian failure and menopause, lack of chronic and disabling mental illness, lack of gender identity disorder, suffering from infertility at least for one year and having no foster children. The inclusion criteria in the infertile females group included : ages 16 to 50 years old, living with spouse, elapsing at least two years of the date of marriage, having children, lack of chronic and disabling mental illness, lack of pregnancy at the moment, occurring no stressful event over the previous month, not being in the postpartum period.

The effort was to make the inclusion criteria of two groups similar in order to conform the samples. A three-part questionnaire was used in order to collect data. The first part included questions about demographic characteristics of subjects such as (age, occupation, education, spouse education, 
marriage duration, infertility duration) and the second part contained Spanier's Dyadic adjustment questionnaire and the third part included Female Sexual Function Index questionnaire. The Spanier's Dyadic adjustment questionnaire contains 32 questions which has been conducted by Graham Spanier in a 5-degree Likert format. Factor analysis shows that this scale measures four dimensions of relationship. These four dimensions are as follows: Satisfaction, dyadic correlation, reciprocal agreement and love expression. The validity and reliability of this implement has been verified in Iran (15).

Female Sexual Function Index (FSFI): It contains 19 questions which measures female sexual function in 6 domains included: Desire, Mental stimulation, Satisfaction, Arousal, Orgasm and Pain. This scale has been conducted by Rosen and her colleagues in 2000 and validated by sexual arousal disorder in a female group. The validity and reliability of this implement has been verified in $\operatorname{Iran}(16)$. Data analysis using SPSS software and descriptive and inferential statistics including the mean and standard deviation were done by using U Mann Whitney Test.

\section{FINDINGS}

The result of this study represented that the majority numbers of subjects in both fertile and infertile female group were 26-30 years old. The most frequency during marriage was (40\%) in 6-10 years fertile females and (49.2\%) in 2-5 years infertile ones. Most of the fertile and infertile females were housewives. The most frequency in fertile females education having Bachelor and higher degree was (37.5\%) and in infertile females having Diploma degree was $(37.5 \%)$ and the most frequency in both fertile and infer tile's spouse education was Diploma degree. The mean and standard deviation of dyadic adjustment and its sub scales are given in table number 1 and the mean and total ranks in table number 2 .

Table 1: mean and standard deviation in dyadic adjustment and its sub scales

\begin{tabular}{cccc}
\hline Dyadic adjustment and its sub scales & Number & Mean & Standard deviation \\
\hline Total dyadic adjustment & 240 & 1.13 & 18.74 \\
Dyadic satisfaction & 240 & 33.47 & 6.96 \\
Reciprocal correlation & 240 & 15.87 & 4.19 \\
Reciprocal agreement & 240 & 45.88 & 8.72 \\
Love expression & 240 & 11.65 & 2.75 \\
Total & $\mathbf{2 4 0}$ & $\mathbf{1 . 5 0}$ & $\mathbf{0 . 5 0}$ \\
\hline
\end{tabular}

Table 2 : Results of Rank table

\begin{tabular}{ccccc}
\hline $\begin{array}{c}\text { Total dyadic adjustment and } \\
\text { its sub scales }\end{array}$ & Group & Number & $\begin{array}{c}\text { The mean of } \\
\text { ranks }\end{array}$ & Total Ranks \\
\hline \multirow{2}{*}{ Total dyadic adjustment } & Fertile & 120 & 123.83 & 1486 \\
& Infertile & 120 & 117.17 & 1406 \\
\hline \multirow{2}{*}{ Dyadic satisfaction } & Fertile & 120 & 120.52 & 14462.50 \\
& Infertile & 120 & 120.48 & 14457.50 \\
\hline \multirow{2}{*}{ Reciprocal correlation } & Fertile & 120 & 110.38 & 13246 \\
\hline \multirow{2}{*}{ Reciprocal agreement } & Infertile & 120 & 130.62 & 15674 \\
\hline \multirow{2}{*}{ Love expression } & Fertile & 120 & 132.93 & 15951.5 \\
& Infertile & 120 & 108.07 & 12968.5 \\
\hline & Fertile & 120 & 111.85 & 13421.5 \\
\hline
\end{tabular}

Table 3: The U Mann Whitney Test to measure dyadic adjustment and its sub scales

\begin{tabular}{cccccc}
\hline & $\begin{array}{c}\text { Total dyadic } \\
\text { adjustment }\end{array}$ & $\begin{array}{c}\text { Dyadic } \\
\text { satisfaction }\end{array}$ & $\begin{array}{c}\text { Reciprocal } \\
\text { correlation }\end{array}$ & $\begin{array}{c}\text { Reciprocal } \\
\text { agreement }\end{array}$ & $\begin{array}{c}\text { Love } \\
\text { expression }\end{array}$ \\
\hline $\begin{array}{l}\text { U Mann } \\
\text { Whitney }\end{array}$ & 6.80 & 7.19 & 5968 & 5.70 & 6161.5 \\
\hline
\end{tabular}




\begin{tabular}{cccccc}
\hline$Z$ & -0.74 & -0.005 & -2.26 & -2.77 & -1.94 \\
$\begin{array}{c}\text { Significant } \\
\text { difference }\end{array}$ & 0.47 & 0.99 & 0.02 & 0.005 & 0.05 \\
\hline
\end{tabular}

The U Mann Whitney test was used in order to compare the dyadic adjustment in fertile and infertile females. The results of U Mann Whitney test represent that there is no significant difference among the rate of dyadic consistence in fertile and infertile female, referring to Be'sat hospital of sanandaj. According to the results, the sub scale of dyadic satisfaction is not also significant, however other sub scales of dyadic adjustment are significant.

The table number 4 illustrates the mean and standard deviation of subject's sexual function and table number 5 illustrates the mean and standard deviation of the sub scales of sexual function in both fertile and infertile female's group. In table number 6 the results of ranks for the female's sexual function index and their sub scales are also illustrated.

Table 4: the comparison of the mean and standard deviation of subject's sexual function

\begin{tabular}{cccc}
\hline Female Sexual Function & Frequency & Mean & Standard deviation \\
\hline Fertile & 120 & 56.2167 & 18.2260 \\
Infertile & 120 & 57.9333 & 11.8262 \\
\hline
\end{tabular}

Table 5: the mean and standard deviation in the sub scales of sexual function in both fertile and infertile females

\begin{tabular}{ccccc}
\hline Variable & Group & Frequency & Mean & Standard Deviation \\
\hline \multirow{2}{*}{ Sexual function } & Fertile & 120 & 56.2167 & 18.226 \\
& Infertile & 120 & 57.9333 & 11.826 \\
\hline \multirow{2}{*}{ Desire } & Fertile & 120 & 6.7000 & 1.553 \\
& Infertile & 120 & 6.7833 & 1.650 \\
\hline \multirow{2}{*}{ Mental stimulation } & Fertile & 120 & 13.1667 & 6.402 \\
& Infertile & 120 & 13.3167 & 3.819 \\
\hline \multirow{2}{*}{ Vaginal moisture } & Fertile & 120 & 9.6000 & 3.802 \\
& Infertile & 120 & 10.6000 & 3.098 \\
\hline \multirow{2}{*}{ Orgasm } & Fertile & 120 & 9.0500 & 3.360 \\
& Infertile & 120 & 9.0667 & 2.499 \\
\hline \multirow{2}{*}{ Satisfaction } & Fertile & 120 & 11.3333 & 4.487 \\
& Infertile & 120 & 11.3500 & 3.424 \\
\hline \multirow{2}{*}{ Pain } & Fertile & 120 & 6.3667 & 3.562 \\
& Infertile & 120 & 6.8167 & 2.989 \\
\hline
\end{tabular}

Table 6 : The results of Ranks for Female Sexual Function Index and its sub scales

\begin{tabular}{ccccc}
\hline Variable & Group & Number & The mean of the Ranks & Total Ranks \\
\hline \multirow{2}{*}{ Sexual function } & Fertile & 120 & 121.55 & 14585.50 \\
& Infertile & 120 & 119.45 & 14334.50 \\
\hline \multirow{2}{*}{ Desire } & Fertile & 120 & 116.98 & 14037.50 \\
& Infertile & 120 & 124.02 & 14882.50 \\
\hline \multirow{2}{*}{ Mental stimulation } & Fertile & 120 & 119.77 & 14272.50 \\
& Infertile & 120 & 121.23 & 14547.50 \\
\hline \multirow{2}{*}{ Vaginal moisture } & Fertile & 120 & 110.45 & 13254.50 \\
& Infertile & 120 & 130.55 & 15665.50 \\
\hline \multirow{2}{*}{ Orgasm } & Fertile & 120 & 125.26 & 15031.00 \\
& Infertile & 120 & 115.47 & 13889.00 \\
\hline
\end{tabular}




\section{Pain}

Fertile

120

116.35

124.65

13962.50

14957.50

The U Mann Whitney test was used in order to compare the total sub scale of sexual function both fertile and infertile females. The results given in table number 8 illustrates that there is no significant difference among the rate of sexual function in both fertile and infertile female's referring to Be'sat hospital of Sanandaj. Also according to the above table, only the sub scale of vaginal moisture is significant and other sub scales of sexual function are not significant.

Table number 8: U Mann Whitney for female sexual function and its sub scales

\begin{tabular}{ccccccc}
\hline & $\begin{array}{c}\text { Total scale of Female } \\
\text { Sexual Function Index }\end{array}$ & Desire & $\begin{array}{c}\text { Mental } \\
\text { stimulation }\end{array}$ & $\begin{array}{c}\text { Vaginal } \\
\text { moisture }\end{array}$ & Orgasm & Pain \\
\hline U Mann & 7074.500 & 6.778 & 7.112 & 5.994 & 6.629 & 6702.50 \\
$\begin{array}{c}\text { Whitney } \\
\text { Z }\end{array}$ & -0.234 & -0.808 & -0.164 & -2.264 & -1.077 & -0.932 \\
$\begin{array}{c}\text { Significant } \\
\text { difference }\end{array}$ & 0.815 & 0.419 & 0.870 & -0.024 & 0.281 & 0.351 \\
\hline
\end{tabular}

\section{DISCUSSION AND CONCLUSION}

This study represents that there is no significant difference among the rate of dyadic adjustment and sexual function in both fertile and infertile females. In the research conducted by 7 are 8 colleagues (2015) as the comparison of dyadic satisfaction in both fertile and infertile female's and it's correspondence to the sexual problems, the results has represented that there is no significant statistics differences among the fertile and infertile couples regarding the dyadic satisfaction score it is in line with the present study (17).

In the research conducted by Besharat and colleagues (2015) determining the consistency with infertility as a topic based on the relationship quality, couple's beliefs and social support, the results represent that there is a negative relation between dyadic problems and consistency and the results obtained are in line with the present study (18). Repokari and colleague's study in (2007) also confirms that the infertility treatment stages could not be a threat to the dyadic adjustment and dividing the stress of it among couples could even strengthen the dyadic relation which is in line with the present study (19). Also the results of this study corresponds with active research of kalkhuran and colleagues (2011), Junaydi and colleagues (2009), shaker and colleagues (2006), pazande and colleagues (2005), zia-Ul-Hag and colleagues (2012), Mazaheri and colleagues (2001) (2, 7, 3,20, 21, $8)$.

Aman Allahi fard and colleagues research (2012) about the comparison of dyadic satisfaction between fertile and infertile females represented that infertile female's has less dyadic satisfaction than fertile female's which is not in line with the present study (22). The Tamanai Fard's research (2011) represented that there is a significant difference among mental health, dyadic adjustment and infertile and fertile female's coping response. In a comparison the infertile females have less mental health and dyadic adjustment than fertile ones which is not in line with this study (23). Monga and colleagues research in (2004) also represented that the rate of dyadic satisfaction in infertile couples is less than fertile ones which is not in line with this current study (24). Aydogan and colleagues research done in turkey in (2013) concerning the effect of infertility and infertility duration on female sexual function represented that is a comparison between the fertile and infertile sexual function. There was no difference in any parameters of FSFI questionnaire including pleasure, Arousal, Mental stimulation, orgasm, satisfaction and pain, the result of this research is in line with the present study (25) in another research conducted by Gulcan Gulec and colleagues in turkey (2011), there was no significant difference among infertile couples and the fertile couple control group. The result of this research is in line with the presser study (26).

Also in a research conducted by drosdzol (2009) towards evaluation of dyadic and sexual satisfaction in infertile females of Poland, the results of the research represented that the parameters of life quality 
in infertile females were less than the control group in all cases but there were no significant difference among the sexual function in infertile and fertile females and the result of this research is in line with the present study (27) in a research conducted by Ashraf and colleagues in (2015), towards the effect of infertility on female sexual function referring to the public and private treatment centers of Ilam, the results represented that there is a significant difference among the infertile and fertile sexual function and the sexual function in infertile females was less than fertile ones, the result of this research doesn't correspond to the present study (28).

In a research conducted by Ilay and colleagues in (2015), towards the effect of the cause of infertility and depression on female sexual function in turkey, the results represented that there was no significant difference in infertile sexual function with various causes of infertility, But there was a significant relation between the severity of depression and infertile sexual function disorder. The results of this research doesn't correspond to the present study (29) in order to determine that why fertile females have gained less Ranks than infertile ones in some sub scales of dyadic adjustment according to the table number 4 , we could mention to these below researches:

In a research conducted by seraj and colleagues in (2014) towards the correlation among the difficulty of transition to parenthood and dyadic adjustment and comparing it to the female's having their first or second child, the result represented that there was an inverse relationship between the difficulty of transition to parenthood and dyadic adjustment (30) in a research conducted by shakerian $63,2 \%$ of Iranian healthful females have had problem in their dyadic relations. It has also been specified that female's having high dyadic adjustment in their life, have high behavioral and physical health as well as their children. Various factors impact on dyadic satisfaction such as: contextual, demographic and socio-cultural factors, child birth and the number of children (31). The transition to parenthood is a physical, psychological and very crucial period in couple's life. Through this transition the couple's relation faced with multiple variations and hence it could decrease the dyadic satisfaction. Recently the US Government has spent several hundred million dollars for health promotion in the recent parent relation. This massive investment represents relation. That the recent parent's relationship is in a high risk concerning the less of satisfaction and dyadic relation dissolution (32).

in a research conducted by Lawrence and colleagues (2008) the quality of recently married couple's relationship including couples possessing no children and those having children (has become parents), which has been studied through a period of $3-4$ years, had represented loss of couple's satisfaction and emotions expression. One of the variables changing most in the parent group was downward sloping through joint activities time. Of course it is clear that the child care reduce necessarily the joint activities time (33)

the researches show that having one child affect negatively on some aspects of relations between spouses. Various explanations are provided for this satisfaction reduction, including the development of social and economic needs, reduction of the time which spouses spend together and disagreement about raising children (34). children don't have negative effect on relation between spouse by themselves but they cause increasing of the social and economic pressure and reducing the time which spouses spend together. Parents facing with higher levels of psychological problems such as economic problems, unemployment and lack of adequate social support, have higher levels of stress (35).

We also could say that unlike the past, having children do not benefit today and it further moves towards having the least of children. In order to specifies this matter perhaps we could mention to the assisted reproductive technologies and significant advances in the field of infertility leading to increase in hopefulness which make the infertile individual to experience less problems in dyadic relations. In fact, some researches show that the stages of infertility treatment are not only a threat to dyadic adjustment. The infertile couples are forced to go through infertility crisis together, participate in long-term treatments, make decision in common and share their emotions, therefore this could 
cause them to have equal or even more dyadic satisfaction as fertile couples (36). Since the infertility affects couples as a unit, and treatment requires the male and female collaboration, it is required to take unit effort to establish proper communication between couples. Some couples express a serious destruction in their communication while others feel more dyadic and propinquity satisfaction than before (37). The sexual functions in humans are influenced by complex interplay of factors is childbirth which is one of the most important event of every females life after a period of time. It is also an emotional and dynamic period of individuals' life (38). After the first year of childbirth, most females express the experience of at least one problem related to sexual functions (39).

In a research conducted by Moghimi and colleagues (2012) concerning a comparative study of sexual function after the childbirth in the females first vaginal and cesarean childbirth in Karaj, the results represented that the average scores of performance, satisfaction and sexual disorder (in all aspects) in females giving childbirth through natural childbirth process re better than cesarean and there was a significant difference between the ranks of two groups according to the delivery types (40). Hicks stated that the prevalence of sexual function during postpartum is $22-86$ percent (41). Barret and colleagues stated that sexual function disorders including diminution of libido, lack of orgasm, vaginal dryness, lack of sexual satisfaction, dyspareunia and reduction in frequency of sexual activity after childbirth will increase compared to the time before pregnancy (42). Discharge and vaginal bleeding, perineum illness, hemorrhoids, breast pain and vaginal slippery due to breast feeding along with fatigue caused by sleep disorders, all of which involved in reducing the incentive for sexual activity. Other problematic factors including the fear of baby waking and reducing the feeling of being attractive are changing perceptions of mental or mood change of oneself (1).

Usually a good sexual relationship requires enough time and energy which mothers often need to sleep because of breastfeeding to babies and their protection and spend most of their times on caring for babies (43).

Some of the limitations of this study could include: lack of proper responses to questions on the taboo of sexual function among females in Iran and since the study among females referring to Sanandaj is through the region's particular social-cultural situation, the generalizability to other females is not possible. Also in this study the ages of the fertile females children were not taken into account and may be affected by the results of the study.

Failing to check the performance of infertile females' spouses in our studies, it is advisable to check the infertile females' spouses and also men suffering from infertility in future studies.

\section{Acknowledgements:}

It is necessary for me to express my acknowledgements to dear my professors Ms. Roonak Shahoi , $\mathrm{PhD}$ in Midwifery and Ms. Masoumeh Rezai, gynecologist and infertility specialist who helped me to conduct this study.

\section{REFERENCES}

1) Novak E, Berek J. Novak's Genecology. 14th ed. London: Lippincott Williams \& Wilkins; 2007.

2) Fa'al kalkhoran L, Bahrami H, Farrokhi N, Zera'ati, Tarahommi M. Comparison of anxiety, Depression and Marital Satisfaction in two groups of fertile and infertile women in Tehran . Journal of Reproduction and Infertility. 2012; 12(2): p 157- 163. [Persian].

3) Shakeri J, Hossieni M, Golshani S, Sadeghi Kh, Fizollahy V. Assessment of general health, stress coping and marital satisfaction in infertile women undergoing IVF treatment. J Reprod Infertil. 2006; 7(3):269-75. [Persian].

4) World Health Organization. Available at: http://www.who.com.htm. Accessed: 15 Sep 2012.

5) Roger RH. Human Sexuality. 3rd ed. Mandocino College; 2010. P 69-62.

6) Safarinejad M. Infertility among couples in a population-based study in Iran: prevalence and associated risk factors. Int J Androl 2008; 31 (3): 303-14. [Persian]. 
7) Jonaidy E, Noorani S, Mokhber SH, Shakeri M. Comparing the Marital Satisfaction in Infertile and Fertile Women Referred to the public clinics in Mashhad in 2006- 2007. Iran Obstetrics, Gynecology \& Infertility J. 2009; 12(1): p 16- 17. [Persian].

8) Mazaheri MA, Kayghobadi F, Faghihi Imani Z, Ghashang N, Pato M. Problem solving strategies and marital adjustment in infertile and fertile couples. J Reprod Infertile. 2001; 2(4): 22-32. [Persian].

9) Soltani M, Shaeeri M, Roshan R. The effect of excitement focused on increasing marital couples infertile couples. Behavioral Sciences J,2012; 6. p 383-389. [Persian].

10) Greef, A. bruyne, T. Conflict management style and marital satisfaction. Journal Sex and Marital Therapy.2000; 26, 321-34.

11) Gibson DM, Myers JE. Gender and infertility: a relational approach to counseling Women J Counselling \& Development. 2011; 78: (4) 11-14.

12)Horne S, Zimmer- Gembeck MJ. The female sexual subjectivity inventory: development and validation of an instrument for late adolescents and emerging adults. Psychol Women Q J. 2005; 30:125-38.

13) Hirsch AM, Hirsch SN. The long term psychosocial effects of infertility. J Obstetric Gynecol Neonatal Nurse. 2005; 25(6):517-22.

14) Anderson KM, Sharpe M, Rattray A. Irvin D. Distress and concerns in couples to a specialist infertility clinic. J Psychcosom Res; 2003. 54(4):353-5.

15) Sanai Zaker B. Family and marriage scales. $2^{\text {nd }}$ ed. 2008.

16) Mohamadi KH, Heidari M, Faghih Zadeh S. The validity of Persian version of the scale as the Female Sexual Function Index.

17) Zare' Z, Golmakani N, Amirian M, Mazloom R, La'l Ahangar M. Compare marital satisfaction in fertile and infertile couples and their relationships with sexual problems. Iran Obstetrics and Gynecology and Infertility J. 2015; 18(143) :1-10. [Persian].

18) Besharat M, Lashkari M, Reza Zadeh M. Exploration of coping with infertility on the quality of the relationship, couples beliefs and social support. Family Psychology J; 2014. 1(2): 51-41.

19) Repokari L, Punamaki RL. Infertility treatment and marital relationships: a 1year prospective study among successfully treated ART couples and their controls. Hum Reprod; 2007; 22 (5): 1481-91.

20) Pazandeh, F, Sharghi, SN, Karami Nouri, R, Alavi Majd, H. A comparative study of psycho-social aspect between infertile and fertile women referring to health care center and infertility center in Tehran. Pejouhandeh. 2005; 9 (6):355-60 [Persian].

21) Zia Alhagh M, Hasan Abadi H, Ghanbari B, Modarres M. Effect of emotion focused couple therapy on marital adjustment. Family Studies J. 2013; 8(29): 49-66. [Persian].

22) Amanelahifard. A. Nikbakht, R, Hoseini, MA, Ahmadi, S. Hoseini, Z. The comparison of marital satisfaction and quality of life between fertile and infertile women. Biannual J. 2012; 2(1):75-88 [Persian].

23) Tamanaei far M. Comparison study of mental health, marital adjustment and coping responses in fertile and infertile women. Clinical Psychology and personality J, 2011; 4: 51-60.

24) Monga, M, Alexandrescu, B, Katz, SE, Stein, M, Ganiats, T. Impact of infertility on quality of life, marital adjustment and sexual function. Urology.2004; 63(1): 126-30.

25) Aydogan Kirmizi D, Iris A, Taner CE. Effects of infertility and infertility duration on female sexual functions. Arch Gynecol Obstet. 2013 Apr; 287(4): 809-12.

26) Güleç G, Hassa H, Yalçın EG, Yenilmez C. The effects of infertility on sexual functions and dyadic adjustment in couples that present for infertility treatment. [Article in English, Turkish] $\mathrm{J}$ Sex Marital Ther.Turk Psikiyatri Derg. 2011 Fall; 22(3):166-7 2015 Jan 28:1-9.

27) Drosdzol A, Skrzypulec V. Quality of life and sexual functioning of Polish infertile couples. Turk Psikiyatri Derg. 2011 Fall; 22(3):166-76.

28) Ashraf DM, Ali D, Azadeh DM. Effect of Infertility on Sexual Function: A Cross-Sectional Study' J Clin Diagn Res; 2015 May; 9(5):QC01-3. 
29) Ilay G, Kucur Suna K, Aysenur A, Kerem Han G, Eda Ulku U, Pasa U, et al. Effects of Infertility Etiology and Depression on Female Sexual Function. Arch Gynecol Obstet. 2013 Apr; 287(4):809-12. Epub 2012 Nov 24.

30) Seraj F, Noorani Sh, Shakeri M. The correlation between the difficulty of the transition to parenthood and marital satisfaction in women and compares it with women the first and second child. Psychiatric Nursing J.2014 Nov; 2(3):1-1 [Persian].

31) Shakerian A, Fatemi A, Farhadian M. The relationship between personality traits and marital satisfaction. Kurdistan University of Medical Sciences J, 2011; 16(1):92-99.

32) Doss, B. The effect of the transition to parenthood on relationship quality: an 8 year prospective study. J Pers Soc Psycol;2009. 96(3):601-619.

33) Lawrence, E. Cobb, RJ. Marital Satisfaction across the transition to parenthood. J Fam Psychol;2008. 22(1):41-50.

34) Schulz, M. Promoting Healthy Beginnings: A Randomized Controlled Trial of a Preventive Intervention to Preserve Marital Quality during the Transition. Journal of Consulting and Clinical Psychology.2006 Feb; 74(1): 20-31.

35) Delmore-Ko, P. Pancer, S. Hunsberger, B. Pratt, M. Becoming a parent: the relation between prenatal expectations and postnatal experience. Journal of Family Psychology.2000; 14: 625-640.

36) Zamanian A. Fundamental changes in the family in recent decades in Iran. $1^{\text {st }}$ ed. Tehran. 2008

37) Fooladi, E. Danesh, M. Kashfi, F. Khani, S. Mohammadpour, RA. Study the attitudes in infertile couples towards marital adjustment and infertility in referred to infertility center in Tehran. $\mathbf{J}$ Mazand Univ Medl Sci.2006; 16(55):131-7.

38) Rowland M. Breast feeding and sexuality immediately postpartum. CFPJ 2005; 51(10): 1367.

39) Susan Scott. Essentials of maternity newborn women's health care nursing. Philadelphia: Lippincott Williams. 2007; 145-163.

40) Moghimi Hanjani S, Mehdizadeh Z. Comparison of sexual function after childbirth in primiparous women experiencing vaginal delivery and caesarian section in karaj city. Quarterly of the Horizon of Medical Sciences. 2013; 18(5). P 224-231.

41) Hicks TL, Goodall SF, Quattrone EM, Lydon-Rochelle MT. Postpartum sexual functioning of delivery: Summary of the evidence. J Midwifery Women's Health 2004; 49(5): 430-436.

42) Barrett G, Peacock J, Victor CR, Manyonda I. Cesarean section and postnatal sexual health. Birth J 2005; 32(4): 306 - 311.

43) Avery MD, Drukett L, Frantzich CR. The experience of sexuality during breast feeding among primiparous women. J Midw Women's Health 2000; 45(3): 227-237. 